\title{
Student Nurses Well-being and the Impact of Mindfulness (SWIM)
}

\author{
Phil Noone ${ }^{1 *}$, Mary Gannon ${ }^{1}$, Lorraine Mee ${ }^{1}$, Siobhan Smyth ${ }^{1}$, John Ivory ${ }^{2}$ and Evan Byrne ${ }^{3}$ \\ Lecturer, School of Nursing and Midwifery, National University of Ireland, Ireland
}

Researcher, School of Nursing and Midwifery, National University of Ireland, Ireland

Registered Psychiatric Nurse. Staff Nurse, Galway/Roscommon Mental Health Services

*Corresponding author: Phil Noone, Lecturer, School of Nursing and Midwifery, National University of Ireland, Galway. Ireland.

Received Date: April 03, 2020

Published Date: June 12, 2020

\begin{abstract}
Mindfulness is an emerging practice in health care [1]. Empirical evidence suggests that Mindfulness programmes and practices can positively impact on physical and psychological health and contribute to overall well-being in health settings [2]. A more recent study by King C, et al. [3], showed that mindfulness practice exercises increased staff positivity, decreases their stress, and helps maintain calmness among staff.

Furthermore, systematic reviews highlight that improved sense of well-being is shown amongst healthcare providers who integrate Mindfulness Practice into their personal and professional lives [4]. It is imperative that student nurse's develop self-care strategies and that their well-being is given a more prominent focus in nursing research and education. This qualitative descriptive study was a pilot that aimed to introduce a mindfulness practice unit into the first- and third-year undergraduate nursing programme in an Irish University. First year nursing students at the start of their programme and third year nursing students prior to the start of their internship placement were selected as these have been identified as periods of increased anxiety and change [5,6]. Findings suggest that Mindfulness can offer nursing students a practical toolkit that supports and enhances their well-being.
\end{abstract}

Keywords: Mindfulness; Well-being; Student nurses; Nursing students; Mental health

\section{Introduction}

Stress, burnout and high attrition rates in nursing are a concern [7]. Burnout and compassion fatigue are not limited to nursing but is an intrinsic part of professional life $[1,8,9]$. Irving JA, et al. [10], estimated that $40 \%$ of nurses report occupational burnout and compassion fatigue which can impact negatively on caring and therapeutic relationships which are central to the profession. 'Moral distress' is a cause of stress for nurses working in Emergency Departments [11,12], and Ankers MD, et al. [13], identified that self-imposed pressure to complete tasks impacted negatively on graduate nurses' ability to listen to patients.

Nurse's deal with stressful situations on a daily basis, unfortunately it is not always possible to walk away from patients, and indeed colleagues. Mindfulness provides a tool for dealing with stress while working.

Mindfulness can be described as a way of being with one's experience as it occurs in the present moment through cultivating awareness, exercising one's capacity for paying attention, on purpose and non-judgementally [14]. Mindfulness practice promises increased awareness, calmness and empathy [15]. Research further suggests that people who practice Mindfulness on a regular basis are better able to regulate their well-being, by enhancing greater emotional awareness, understanding and acceptance [16]. It is also suggested that the ability to regulate one's internal emotional experience in the present moment may enhance positive overall mental health $[8,17]$. Therefore, formally 
integrating Mindfulness into nurse education and practice has the potential to enhance compassionate nursing qualities and positively contribute to improved patient outcomes [1], increased job satisfaction, and enhanced health and well-being [9].

Evidence shows that nurses who practice mindfulness experience an increased well-being and openness to others [18].

Results from a randomized control pilot study following an eight week Mindfulness Based Stress Reduction intervention suggested that it may be effective in reducing stress and enhancing the quality of life and self-compassion in health care professionals [9]. These studies point to Mindfulness as a potential means to address the challenges in health care and, in particular, within nursing. However, this remains an undeveloped area in nurse education in an Irish context.

This qualitative descriptive study aimed to introduce a mindfulness practice unitinto the first and third year undergraduate nursing programme in an Irish University. First year nursing students at the start of their programme and third year nursing students prior to the start of their internship placements were selected as these have been identified as periods of increased anxiety and change $[5,6]$.

\section{Materials and Methods}

A descriptive qualitative approach was used, based on the belief that multiple perceptions of reality exist and that individuals can experience a phenomenon in completely different ways [19].

This pilot study aimed to capture and evaluate general nursing, mental health nursing and midwifery students' experiences of participating in a mindfulness practice programme delivered over four weeks in a four-year BNS undergraduate programme in an Irish university setting.

A convenience sample of all consenting first year general nursing, mental health nursing and midwifery students and those registered on the complimentary therapies module in third year was utilised.

The mindfulness programme was delivered by a qualified mindfulness practitioner that has authored several books including: 'The Nurses Guide to Cultivating Mindfulness and Compassion' and 'The Mindful Nurse - Using the Power of Mindfulness and Compassion to Help You Thrive in Your Work' [15].

\section{Data collection methods included reflective diaries and focus group (FG) interviews}

Reflective Diaries are a multidimensional tool that can exist in a variety of forms [20] and serve as a pedagogical tool for the encouragement of reflection, critical self-appraisal for the students [17]. "Diary writing is both a product and a process that helps us 'capture an experience, record an event, explore our feelings', or make sense of what we know" Boud [20]. Reflective practice is a coping and learning strategy used within all nursing and midwifery programmes. Reflective diaries used in this study helped capture the student experiences of mindfulness using an approach that is familiar to them.

The participants completed diaries at three different intervals (start, middle and end of the teaching unit) using the Kolb's Cycle (1984) as a specific framework to guide them with 3rd years only. Participants reflective entries served as a learning tool for the improvement of learning by creating a connection between theory and practice [21] thus helping to achieve the study's aim.

While multiple opportunities were afforded to the students to attend for interview, a focus group interview was conducted with third year students using a semi-structured format to collect data and this was used in the data analysis process.

This focus group was conducted by an independent facilitator, audio-recorded and transcribed verbatim.

Following the provision of the mindfulness practice unit, the focus group interview and the reflective diaries were analyzed using Braun \& Clarke's [22] framework:

Familiarization with the data: This phase involved reading and re-reading the data, to become immersed and intimately familiar with its content.

Coding: This phase involved generating succinct labels (codes) that identified important features of the data that were relevant to answering the research aim. It involved coding the entire dataset, and collating relevant data extracts for analysis.

Searching for themes: This phase involved examining the codes and collated data to identify significant broader patterns of meaning (potential themes).

Reviewing themes: This phase involved checking the participant themes against the dataset to ensure it reflects the data.

Defining and naming themes: This phase involved defining and naming themes.

Writing up: This final phase involved weaving together the analytic narrative and data extracts to answer the research aim. Ethical approval was initially sought from an institution Research Ethical Committee (REC). At all times, the participants' wellbeing was given priority over this research study.

\section{Results and Discussion}

Findings' of the focus group interview and the reflective diaries for the study are presented together below. Some excerpts from the data are included to illustrate the more salient issues.

The first overarching thematic area emerged from the data revealed: Mindfulness: My New Way, captured in sub- thematic areas of: Challenging and Changing; Shifting Awareness to the Present; Re-gaining Care for Self and Others.

\section{Mindfulness: my new way}

The practice of Mindfulness was viewed by the majority of participants as beneficial to personal and professional life. Though 
not without its challenges, there existed a sense of an evolving nature to the practice as illustrated in the thematic areas identified below:

Challenging and changing: Many challenges existed for students as they began to engage in the practice of Mindfulness. Hesitancy and feeling of uncertainty were expressed about the initial sessions, but, over time, the practice started to yield benefits and this encouraged the students to continue, in particular, with the short mindfulness practices.

'Initially, I was uncertain about engaging in mindfulness...' as in the past I struggled with such techniques and in calming my thoughts and busy mind. Curiosity though prompted me to try again'. (011)

'...I thought it would be easier to just be able to just do mindfulness. But it's like you kind of have to keep practicing in order to you know.... be able to anchor yourself down to do the techniques and stuff'.(FGP5).

'I found it more difficult than I expected and did not enjoy it'. (032)

'This is hard for me...My mind wanders and I get bored. I enjoy it for a couple of minutes and then get distracted with everything I have to do after class'. (037)

Shifting awareness to the present: This subtheme indicates that participants demonstrated a greater awareness of being in 'auto-pilot mode', caught up in their thoughts and worries in relation to college work and life generally.

'I have discovered I live my life on autopilot $99 \%$ of the time, I'm seeing what I'm really thinking and feeling'. (036)

'I realised my mind wanders so much. So it's like you do have to get disciplined with yourself to stay focused instead of being off thinking of all the different things you've to do'. (FGP 6)

'From the very first class I was able to step out of my thoughts, essentially like stepping out of a glass box filled with thousands of thoughts'. (043)

'...helped me to become more self-aware and more importantly have given me the tools needed to purposely analyse my conscious mind, identify recurring thoughts and emotions and step back from the noise of everyday life and stress.' (026)

'I realised my mind wanders so much. So it's like you do have to get disciplined with yourself to stay focused instead of being off thinking of all the different things you've to do'. (FGP 6)

Re-gaining care for self and others: This final sub-theme incorporates the benefits of Mindfulness Practice for enhancing self-care and extending this to others in professional nursing.

'I felt very Zen after week two and it put me in a great mood for the week ahead - I was filled with positivity'. (013)
'I noticed my movements in completing tasks were slower, tone of voice was softer and even, focus was settled and I felt settled in myself'. (011)

'I'm more awareness of my emotions and I'm able to control them better'. (036)

'I find I'm waking during the night thinking about all the assignments' but this week my sleep has improved'. (038)

'When driving this morning when the extra slow driver was getting on my nerves, I remembered what ... said and I thought of accepting it and be non-judgemental. I actually felt better afterwards'. (019)

'In clinical placement... 'anytime I get stressed or anxious , I turn to the 'STOP' technique or the ' 1 breath 2 feet 'technique and the 'cultivating kindness' practice and whatever situation I am in becomes less stressful and my mind is in a better headspace to resolve it'. (026)

The second overarching thematic area revealed:

\section{Facilitators and barriers to the integration of mindfulness practice}

Facilitators to Mindfulness practice as identified by the participants included: the facilitation skills, experience and knowledge of the Mindfulness teacher, the simplicity and usability of the practices, including on-line 'Apps and the environment where the practice takes place. Barriers included group size.

'I liked these because I looked at them from a realist's point of view and thought about how they would benefit me as a student nurse on placement on a busy ward'. (013)

'There was almost too many people in the group, people were giddy and it was easy to get distracted'. (013)

'We have an instructor in college who is explaining research behind mindfulness practice'. (032).

'It was a mindfulness app and it's good because it kind of guides you, you know. It's great when we're here in the class with [mindfulness teacher] and she's able to guide us through it. And then in between say in between practices she will explain why we're doing this or why we're doing that. So, when you're at home on your own its difficult you know when you don't have somebody to guide us. So, the app is very good. It guides you'. (FG 1)

\section{Conclusion}

This pilot study offers a snapshot glimpse into its future potential in recognition that the research and development of Mindfulness within nursing is in its infancy.

The study aimed to capture the reported experiences of general nursing, mental health and midwifery students within one Irish university setting in relation to using Mindfulness practice during their college and clinical placements. In recognition of the 
limitations of this small pilot study, findings indicate that despite the challenges of practising Mindfulness, participants, nonetheless, demonstrated personal and professional benefits that included dealing with stressful situations in college and clinical areas, better emotional control, enhanced sleep and a recognition of the need to take care of themselves in everyday life. It can, therefore, be claimed that Mindfulness practice has potential benefits for nurse well-being and for the patients they interact with on a daily basis. In addition, nursing could offer a contribution to the development of Mindfulness in health care. For this reason, more research is required on the impact of Mindfulness in the educational and health settings.

\section{Acknowledgements}

We would like to extend our thanks to the participants who took part in this study and gave so freely of their time and commitment. This research was grant aided by Seed Fund Research Grant from the School of Nursing and Midwifery, NUI Galway, who supported this research.

\section{Conflict of Interest}

No conflict of interest has been declared by the authors.

\section{References}

1. White L (2013) Mindfulness in nursing: an evolutionary concept analysis. J Adv Nurs 70(2): 282-294.

2. Matchim Y, Armer JM, Stewart BR (2011) Effects of mindfulness-based stress reduction (MBSR) on health among breast cancer survivors. West J Nurs Res 33(8): 996-1016.

3. King C, Rossetti J, Smith TJ, Raison M, Gallegos D, et al. (2019) The Effects of a Mindfulness Activity on Nursing Service Staff Perceptions of Caring Behavior in the Workplace. J Psychosoc Nurs Ment Health Serv 1(57): 28-36.

4. Kuken W, Byfold S, Taylor RS, Watkins E, Holden E, et al. (2008) Mindfulness-based cognitive therapy to prevent relapse in recurrent depression. J Consult Clin Psychol 76(6): 966-978.

5. Pulido-Martos M, Augusto-Landa JM, Lopez-Zafra E (2011) Sources of stress in nursing students: a systematic review of quantitative studies. International Nursing Review 59(1): 15-25.

6. Duchscher JE (2009) Transition shock: the initial stage of role adaptation for newly graduated Registered Nurses. J Adv Nurs 65(5): 1103-1113.

7. Van der Riet P, Levett-Jones T, Aquino-Russell C (2018) The effectiveness of mindfulness mediation for nurses and nursing students: an integrated literature review. Nurse Educ Today 65: 201-211.
8. Baer RA (2003) Mindfulness training as clinical intervention: A conceptual and empirical review. Clinical Psychology Science and Practice 10(2): 125-143.

9. Shapiro SI, Astin JA, Bishop SR, Cordova M (2005) Mindfulness Based Stress Reduction for Health Care Professionals: Results from a Randomised Trial. International Journal of Stress Management 12(1): 164-176.

10. Irving JA, Park-Saltzmaqn J, Fitzpatrick M, Dubkin PL, Chen A, et al. (2012) Mindfulness Springer Science \& Business Media.

11. Duffy E, Avalos G, Dowling M (2015) Secondary traumatic stress among emergency nurses: a cross sectional study. Int Emerg Nurs 23(2): 53-58.

12. Mahon MA, Mee L, Brett D, Dowling M (2017) Nurses perceived stress and compassion following a Mindfulness Meditation and SelfCompassion training. Journal of Research in Nursing 22(8): 572-583.

13. Ankers MD, Barton CA, Parry YK (2018) A Phenomenological exploration of graduate nurse transition to professional practice within a professional practice within a transition to practice program. Collegian 25(3): 319-325

14. Kabat-Zinn (2013) Full Catastrophe Living. How to Cope with Stress, Pain and Illness using Mindfulness Meditation. Piatkus, London, UK.

15. Sheridan C (2016) The Mindful Nurse: Using the Power of Mindfulness and Compassion to Help you Thrive in Your Work. Rivertime Press: United States of America.

16. Feldman G, Hayes A, Kumar S, Greeson J, Laurenceau JP (2007) Mindfulness and emotion regulation: The development and initial validation of the Cognitive and Affective Mindfulness Scale-Revised (CAMS-R). Journal of Psychopathology and Behavioral Assessment 29: 177-190.

17. Farb NAS, Anderson AK, Segal ZV (2012) The Mindful Brain and Emotion Regulation in Mood Disorders. Can J Psychiatry 57(2): 70-77.

18. Foureur M, Besley K, Burton G, Yu N, Crisp J (2014) Enhancing the resilience of nurses and midwives: Pilot of a mindfulness-based program for increased health, sense of coherence, and decreased depression, anxiety, and stress. Contemp Nurse 45(1): 114-125.

19. Streubert HJ, Carpenter DR (2011) Qualitative Research in Nursing Advancing the Humanistic Imperative. Wolters Kluwer, Philadelphia.

20. Boud D (2001) Using journal writing to enhance reflective practice. New Directions for Adult and Continuing Education 2001(90): 9-18.

21. Dyment JE, O'Connell TS (2011) Assessing the quality of reflection in student journals. A review of the research. Teaching in Higher Education 11: 81-97.

22. Braun V, Clarke V (2006) Using thematic analysis in psychology. Qualitative Research in Psychology 3(2): 77-101. 